\title{
Diagnostic Significance of Fibrin Degradation Products and D-Dimer in Patients With Breast Cancer-Related Lymphedema
}

\author{
Sang Hyeong Ryu, $\mathrm{MD}^{1}$, Sang Won Min, $\mathrm{MD}^{1}$, Jae Ho Kim, MD${ }^{1}$, Ho Joong Jeong, MD, PhD ${ }^{1}$, \\ Ghi Chan Kim, MD, $\mathrm{PhD}^{1}$, Dong Kyu Kim, $\mathrm{MD}^{2}$, Young-Joo Sim, MD, PhD ${ }^{1}$
}

${ }^{1}$ Department of Physical Medicine and Rehabilitation, Kosin University Gospel Hospital, Busan;

${ }^{2}$ Department of Rehabilitation Medicine, Konkuk University School of Medicine, Chungju, Korea

Objective To find out whether levels of fibrin degradation products (FDP) and D-dimer are increased in breast cancer-related lymphedema (BCRL) as in many vascular diseases. FDP and D-dimer have been used in blood tests to help differentiate deep vein thrombosis in the diagnosis of lymphedema. Levels of FDP and D-dimer are often elevated in patients with BCRL.

Methods Patients with BCRL (group I), non-lymphedema after breast cancer treatment (group II), and deep venous thrombosis (group III) from January 2012 to December 2016 were enrolled. Levels of FDP and D-dimer were measured in all groups and compared among groups.

Results Mean values of FDP and D-dimer of group I were $5.614 \pm 12.387$ and $1.179 \pm 2.408 \mu \mathrm{g} / \mu \mathrm{L}$, respectively. These were significantly higher than their upper normal limits set in our institution. Levels of FDP or D-dimer were not significantly different between group I and group II. However, values of FDP and D-dimer in group III were significantly higher than those in group I.

Conclusion Values of FDP and D-dimer were much higher in patients with thrombotic disease than those in patients with lymphedema. Thus, FDP and D-dimer can be used to differentiate between DVT and lymphedema. However, elevated levels of FDP or D-dimer cannot indicate the occurrence of lymphedema.

Keywords Breast cancer related lymphedema, Fibrin degradation products, D-dimer, Deep vein thrombosis

Received July 6, 2018; Accepted September 13, 2018

Corresponding author: Young-Joo Sim

Department of Physical Medicine and Rehabilitation, Kosin University Gospel Hospital, 262 Gamcheon-ro, Seo-gu, Busan 49267, Korea. Tel: +82-51990-6261, Fax: +82-51-990-3181, E-mail: oggum@hanmail.net

ORCID: Sang Hyeong Ryu (http://orcid.org/0000-0002-9233-2525); Sang Won Min (http://orcid.org/0000-0003-3171-2687); Jae Ho Kim (http://orcid. org/0000-0002-3556-4194); Ho Joong Jeong (http://orcid.org/0000-0002-0607-2799); Ghi Chan Kim (http://orcid.org/0000-0002-4954-3175); Dong Kyu Kim (http://orcid.org/0000-0002-9484-6562); Young-Joo Sim (http://orcid.org/0000-0002-0640-8766).

(a) This is an open-access article distributed under the terms of the Creative Commons Attribution Non-Commercial License (http://creativecommons.org/ licenses/by-nc/4.0) which permits unrestricted noncommercial use, distribution, and reproduction in any medium, provided the original work is properly cited. Copyright $\odot 2019$ by Korean Academy of Rehabilitation Medicine 


\section{INTRODUCTION}

Lymphedema is a disease in which an excessive, protein-rich interstitial fluid accumulates due to dysfunction of lymphatic system, leading to inflammation, hypertrophy of adipose tissues, and fibrosis $[1,2]$. Breast cancerrelated lymphedema (BCRL) is usually classified as secondary lymphedema. It is a chronic, delayed edema of the affected upper extremity due to impairment of axillary lymphatic drainage pathway caused by lymph node dissection and radiation therapy during treatment for breast cancer. BCRL is known to occur in about $20 \%$ to $40 \%$ of patients after surgery. It is a major factor that lowers the quality of life of survivors [3].

In clinical practice, we have found that levels of fibrin degradation products (FDP) and D-dimer are often elevated in patients with BCRL. FDP and D-dimer have been used as screening and diagnostic tools in numerous coagulopathies and thrombotic disease. FDP and D-dimer are physiologically involved in blood clotting, growth and remodeling of tissue, wound healing, embryogenesis, blood vessels, and lymphatic vessels [4]. The incidence of upper extremity deep vein thrombosis (DVT) is $4 \%-10 \%$ of all DVTs, with an annual incidence of approximately 0.4 to 1 case per 10,000 persons [5-7].

Reduced movements of the affected upper extremity after surgery and radiation therapy in breast cancer because of pain, scar tissue, fibrosis, and tightness may increase the risk of DVT $[8,9]$. Differential diagnosis of BCRL and DVT is important because complex decongestive therapy (CDT), a well-known treatment of lymphedema, can exacerbate edema caused by DVT [10]. In DVT patients, levels of FDP and D-dimer have been used as screening tools. They are usually elevated [11].

There has been an increase in FDP in lymphedema following rheumatic arthritis. Few reports have studied the association of lymphedema with FDP, D-dimer, and coagulation factors. It has been suggested that damage of lymph-venous system, lymphatic hypercoagulation, lymphatic injury, and stasis may increase lymphatic thrombosis and levels of fibrin and FDP after lymph node dissection [12-15].

Thus, we hypothesized that levels of FDP and D-dimer might be increased in BCRL and lymphedema due to various causes such as thrombotic disease, liver disease, inflammation, malignancy, trauma, pregnancy, recent surgery, and advanced age. Therefore, the objective of this study was to investigate causes of the increase in levels of FDP and D-dimer.

\section{MATERIALS AND METHODS}

\section{Subject}

A retrospective investigation was conducted using medical chart reviews of patients who underwent both FDP and D-dimer analyses from January 2012 to December 2016. This study was approved by the Institutional Review Board of Kosin University Gospel Hospital (No. KUGH 2018-09-016).

All BCRL cases in our hospital were diagnosed at 3 months after surgery for breast cancer by physiatrists according to standard guidelines assisted by clinical features, physical examination, lymphoscintigraphy, peripheral vessel ultrasound, and computed tomography angiography. Exclusion criteria were: (1) patients who were older than 60 years old, (2) patients who had a history of both systemic and focal inflammation, such as lymphangitis or cellulitis of the affected upper extremity, (3) patients who had liver disease and coagulopathy, or (4) patients who took medicine such as anticoagulant and antiplatelet that could affect blood clotting and the level of FDP and D-dimer. Seventy-one patients among 302 patients were included in the BCRL group (group I). Of 265 postoperative breast cancer patients during the same period who were not diagnosed with BCRL, 70 patients were classified as non-lymphedema group (group II) while 52 female patients diagnosed with upper extremity DVT were assigned to group III.

\section{Diagnosis and assessment of BCRL}

In differential diagnosis of BCRL, laboratory studies including complete blood count, serum electrolytes, kidney function, liver function, and thyroid function and evaluation of cardiac function were additionally performed.

Both upper extremity was measured at $3 \mathrm{~cm}$ intervals from the dorsum of the hand to the armpit area (below axilla). A patient whose circumference of the affected upper extremity was $2 \mathrm{~cm}$ or more on the unaffected upper extremity and obstruction, delayed uptake of the flow of the lymphatic fluid on axillary lymph node or dermal backflow was observed in the lymphoscintigraphy was diagnosed as BCRL. These patients complained of clini- 
cal symptoms such as swelling, heaviness, discomfort in daily life, and deterioration of quality of life.

\section{Statistical analysis}

T-test was used to investigate FDP and D-dimer values of lymphedema (cutoff values of 5.0 and $0.5 \mu \mathrm{g} / \mu \mathrm{L}$, respectively, at our hospital). One-way ANOVA was performed for FDP and D-dimer values in each group and post-hoc comparisons were made using the Scheffe and Tukey test. Receiver operating characteristic (ROC) curve was drawn to determine sensitivity and specificity thresholds for FDP and D-dimer values. All statistical analyses were performed using SPSS version 21.0 (IBM, Armonk, NY, USA).

\section{RESULTS}

Mean values of FDP and D-dimer in BCRL (group I) were $5.614 \pm 12.387$ and $1.179 \pm 2.408 \mu \mathrm{g} / \mu \mathrm{L}$, respectively. Values of FDP and D-dimer in group I were statistically significantly (T-test, $\mathrm{p}=0.002$ ) higher than cut off values of FDP and D-dimer in our hospital (5.0 and $0.5 \mu \mathrm{g} / \mu \mathrm{L}$, respectively). In group I, numbers of patients below cutoff values of FDP and D-dimer of our hospital were $43(60 \%)$ and 35 (49\%), respectively.

Mean values of FDP and D-dimer in the non-lymphedema group (group II) were $3.619 \pm 3.386$ and $1.096 \pm 1.054$ $\mu \mathrm{g} / \mu \mathrm{L}$, respectively. In group II, numbers of patients over cutoff values of FDP and D-dimer of our hospital were 22 (31\%) and 29 (41\%), respectively.

Mean values of FDP and D-dimer in DVT (group III) were $19.972 \pm 23.056$ and $4.712 \pm 4.679 \mu \mathrm{g} / \mu \mathrm{L}$, respectively (Table 1). Although values of FDP and D-dimer in group I were higher than those in group II, differences between the two groups were not statistically significant. However, values of FDP and D-dimer were significantly $(\mathrm{p}<0.001)$ higher in group III than those in group I .

Areas under the ROC curve in groups I and III were 0.878 for FDP and 0.859 for D-dimer (Fig. 1). The sensitivity and specificity of FDP were $86.7 \%$ and $70.1 \%$, respective-

Table 1. Values of FDP and D-dimer in each group

\begin{tabular}{cccc}
\hline & Group I (n=71) & Group II (n=70) & Group III (n=52) \\
\hline FDP & $5.6136 \pm 12.387$ & $3.6191 \pm 3.386$ & $19.972 \pm 23.056$ \\
p-value & & 0.207 & $<0.001^{*}$ \\
D-dimer & $1.1790 \pm 2.408$ & $1.0957 \pm 1.054$ & $4.712 \pm 4.679$ \\
p-value & & 0.790 & $<0.001^{*}$ \\
\hline
\end{tabular}

Values are presented as mean \pm standard deviation. FDP, fibrin degradation products. ${ }^{*} \mathrm{p}<0.05$.

(A)

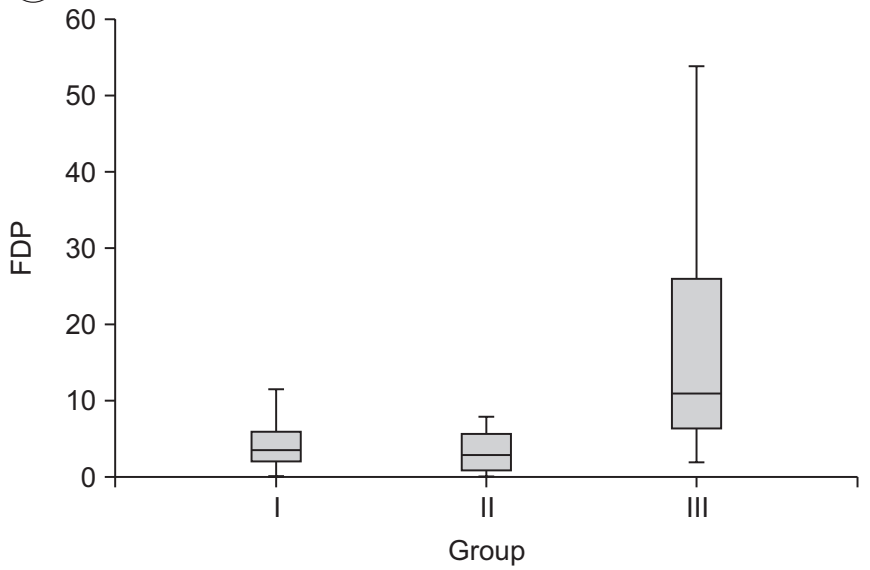

(B)

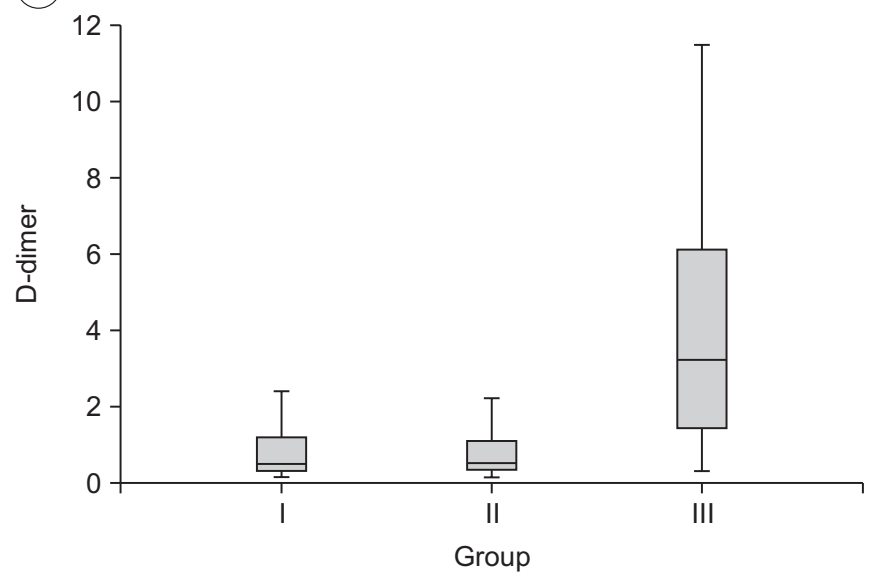

Fig. 1. Comparison of values of FDP (A) and D-dimer (B) in each group. FDP, fibrin degradation products. 
ly, with $5.555 \mu \mathrm{g} / \mu \mathrm{L}$ as a cutoff value. The sensitivity and specificity of D-dimer were $74.5 \%$ and $78.9 \%$ at $1.555 \mu \mathrm{g} /$ $\mu \mathrm{L}$, respectively (Tables 2, 3 and Fig. 2).

\section{DISCUSSION}

FDP and D-dimer are degradation products of crosslinked fibrin, reflecting the ongoing activation of the hemostatic system [16]. Plasminogen is transformed into plasmin by tissue plasminogen activator (tPA) secreted from vascular endothelial cells. This plasmin sequentially decomposes fibrin to form fibrin degradation product. D-dimer is linked to two D domains of this massive fibrinopeptide [4]. It may be increased by age, surgery, pregnancy, inflammation, tumors, congestive heart failure, and coagulopathy. To date, measurement for levels of FDP and D-dimer has been used as a tool to rule out

Table 2. Cutoff values of FDP for sensitivity and specificity in group I and group III

\begin{tabular}{ccc}
\hline FDP & Sensitivity & Specificity \\
\hline 2.785 & 0.933 & 0.507 \\
3.530 & 0.911 & 0.627 \\
4.255 & 0.911 & 0.631 \\
5.555 & 0.867 & 0.701 \\
5.945 & 0.778 & 0.701 \\
6.260 & 0.756 & 0.851 \\
6.695 & 0.733 & 0.864 \\
7.740 & 0.711 & 0.896 \\
\hline
\end{tabular}

FDP, fibrin degradation products.

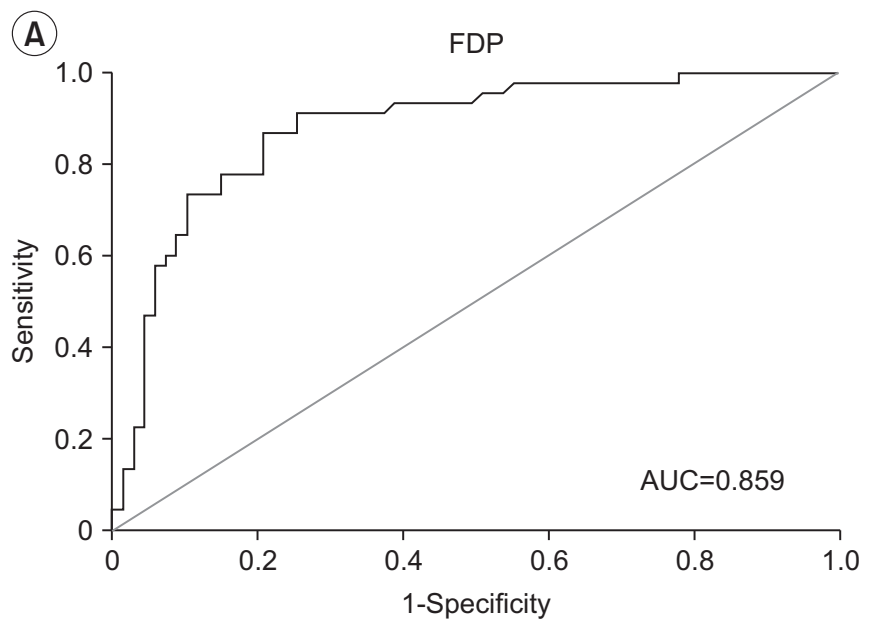

DVT which could be a cause of edema in the diagnosis of BCRL.

The risk of DVT is increased by reduced venous return and venous stasis secondary to post-operation and radiation therapy in breast cancer patients because of insufficient contraction of limb muscles. Although edema could be caused by both BCRL and DVT, there are significant differences in their management and treatment. Anticoagulation with application of compression stocking is the standard treatment for DVT while CDT is the treatment of choice for BCRL. For this reason, appropriate early diagnosis of BCRL and confirmation of concomitant DVT are important. We found that values of FDP and Ddimer were higher in DVT, a thrombotic disease, similar to previous studies. They were significantly difference compared to those in lymphedema. This suggests that measuring levels of FDP and D-dimer can differenti-

Table 3. Cutoff values of D-dimer for sensitivity and specificity in group I and group III

\begin{tabular}{ccc}
\hline D-dimer & Sensitivity & Specificity \\
\hline 0.605 & 0.882 & 0.606 \\
0.835 & 0.824 & 0.690 \\
0.910 & 0.804 & 0.718 \\
1.120 & 0.765 & 0.746 \\
1.275 & 0.745 & 0.761 \\
1.555 & 0.745 & 0.789 \\
1.635 & 0.725 & 0.831 \\
1.900 & 0.686 & 0.845 \\
\hline
\end{tabular}

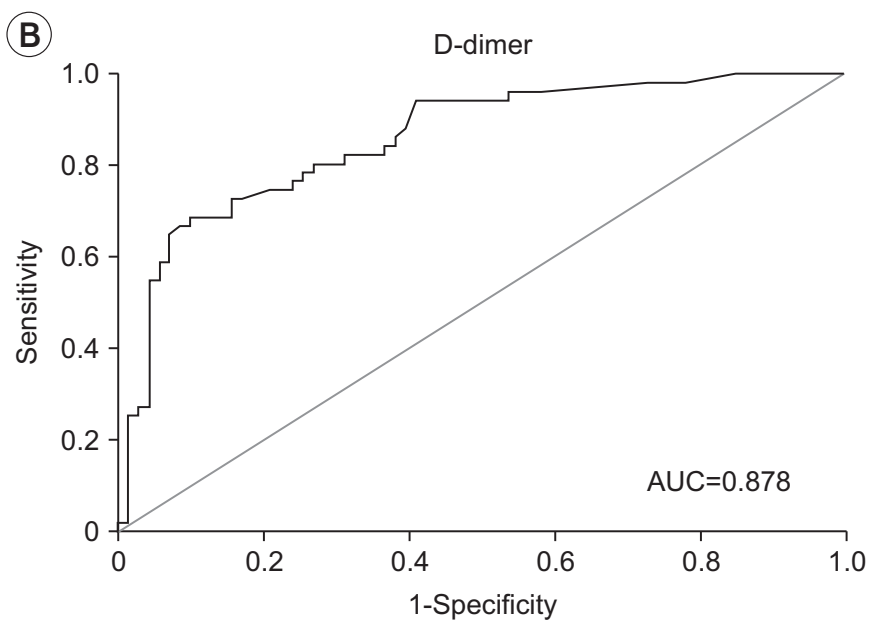

Fig. 2. Receiver operating characteristic curve and AUC of FDP (A) or D-dimer (B) in lymphedema group and deep vein thrombosis group. AUC, area under the curve; FDP, fibrin degradation products. 

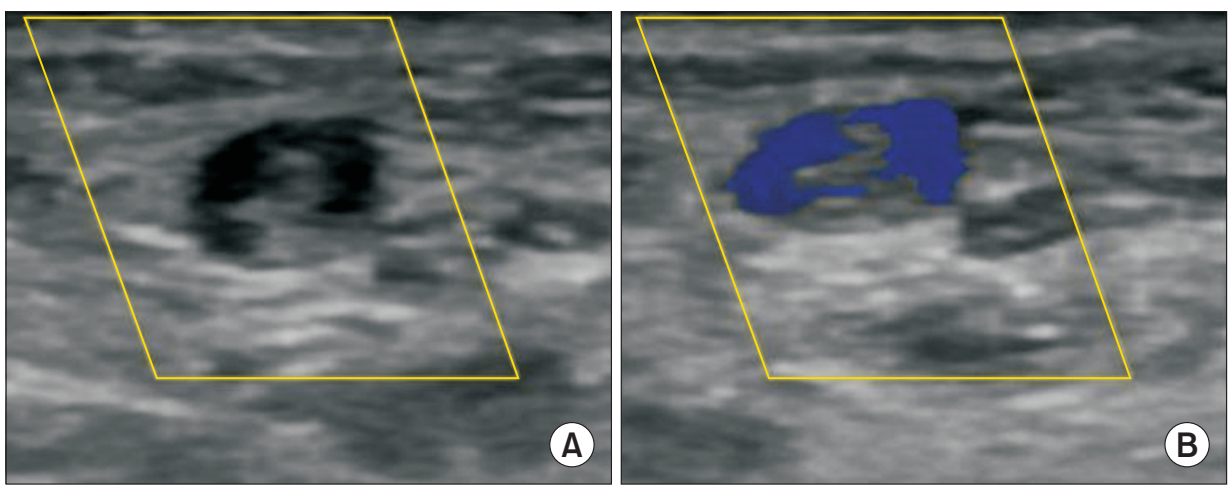

Fig. 3. Ultrasonographic findings of upper extremity deep vein thrombosis. Axial image of axillary vein (A) using color Doppler with compression (B).

ate between DVT and lymphedema and help determine treatment.

FDP and D-dimer may be increased in some conditions such as liver disease, rheumatic disease, inflammation, recent surgery, trauma, and malignancy $[17,18]$. In this study, values of FDP and D-dimer in BCRL were somewhat higher than baseline values of FDP and D-dimer in the T-test using upper normal limits at our hospital. In sheep animal experiments, lymphatic vessel endothelial hyaluronan receptor 1 (LYVE-1) and vascular endothelial growth factor receptor-3 (VEGFR-3) have been detected in damaged lymph node around scapula and popliteal area and expression of a new lymph capillary network with a diameter of $10-40 \mu \mathrm{m}$ is observed [19]. It has been reported that degradation of fibrin and FDP in extracellular matrix is associated with lymphatic germination and expansion of lymphangiogenesis [20-25]. Venous wall thickening of axillary vein was observed on ultrasound in BCRL patients. These findings may be related to slight elevations in concentrations of FDP and D-dimer in plasma, although detailed mechanisms are not well known yet [26]. When levels of FDP and D-dimer are slightly elevated, they could be interpreted as false-positives.

Clinical symptoms and manifestations between lymphedema and DVT may be different. The main symptoms of DVT are acute swelling with skin discoloration and pain whereas lymphedema shows chronic swelling and progressive skin changes $[1,2,4]$. However, it is difficult to differentiate lymphedema from DVT by clinical symptoms and manifestations when lymphedema is at early stage and mild swelling or infection is present. Additional examination may be necessary to confirm lymphatic functions. Lymphoscintigraphy, ultrasonography, venography, and magnetic resonance imaging can be performed for differential diagnosis. Compared to contrast venography, Doppler ultrasonography has sensitivity and specificity both at $82 \%$ [27]. To confirm thrombus and venous incompressibility, Doppler ultrasonography could be useful for initial diagnosis when upper extremity DVT is suspected (Fig. 3).

Limitation of this study included its retrospective nature. Further studies are needed to compare patients with DVT and patients with lymphedema among those diagnosed with breast cancer.

In conclusion, values of FDP and D-dimer were much higher in thrombotic disease than those in lymphedema. Therefore, to measure concentrations of FDP and Ddimer, one of blood coagulation laboratory tests could be used as a helpful marker to differentiate between DVT and lymphedema. Although values of FDP and D-dimer might be somewhat increased compared to their normal reference values, they cannot indicate the occurrence of lymphedema.

\section{CONFLICT OF INTEREST}

No potential conflict of interest relevant to this article was reported.

\section{REFERENCES}

1. Maclellan RA, Greene AK. Lymphedema. Semin Pediatr Surg 2014;23:191-7.

2. Rockson SG. Lymphedema. Am J Med 2001;110:28895.

3. Yang GH, Shim JY. The diagnosis and treatment of lymphedema. J Korean Med Assoc 2013;56:1115-22.

4. Tripodi A. D-dimer testing in laboratory practice. Clin Chem 2011;57:1256-62.

5. Heil J, Miesbach W, Vogl T, Bechstein WO, Reinisch A. 
Deep vein thrombosis of the upper extremity. Dtsch Arztebl Int 2017;114:244-9.

6. Joffe HV, Kucher N, Tapson VF, Goldhaber SZ; Deep Vein Thrombosis (DVT) FREE Steering Committee. Upper-extremity deep vein thrombosis: a prospective registry of 592 patients. Circulation 2004;110:1605-11.

7. Munoz FJ, Mismetti P, Poggio R, Valle R, Barron M, Guil M, et al. Clinical outcome of patients with upperextremity deep vein thrombosis: results from the RIETE Registry. Chest 2008;133:143-8.

8. Wong P, Baglin T. Epidemiology, risk factors and sequelae of venous thromboembolism. Phlebology 2012;27 Suppl 2:2-11.

9. Martinelli I, Bucciarelli P, Mannucci PM. Thrombotic risk factors: basic pathophysiology. Crit Care Med 2010;38(2 Suppl):S3-9.

10. Lasinski BB, McKillip Thrift K, Squire D, Austin MK, Smith KM, et al. A systematic review of the evidence for complete decongestive therapy in the treatment of lymphedema from 2004 to 2011. PM R 2012;4:580-601.

11. Bounameaux H, Schneider PA, Reber G, de Moerloose $\mathrm{P}$, Krahenbuhl B. Measurement of plasma D-dimer for diagnosis of deep venous thrombosis. Am J Clin Pathol 1989;91:82-5.

12. Minari C, Cecconami L, Fioravanti A, Montemerani M, Scola C, Marcolongo R. Lymphoedema of the limbs in rheumatoid arthritis. Clin Rheumatol 1994;13:464-9.

13. Moskovitz AH, Anderson BO, Yeung RS, Byrd DR, Lawton TJ, Moe RE. Axillary web syndrome after axillary dissection. Am J Surg 2001;181:434-9.

14. Lippi G, Favaloro EJ, Cervellin G. Hemostatic properties of the lymph: relationships with occlusion and thrombosis. Semin Thromb Hemost 2012;38:213-21.

15. Brinkhous KM, Walker SA. Prothrombin and fibrinogen in lymph. Am J Physiol 1941;132;666-9.

16. Adam SS, Key NS, Greenberg CS. D-dimer antigen: current concepts and future prospects. Blood 2009; 113:2878-87.

17. Kabrhel C, Mark Courtney D, Camargo CA Jr, Plewa MC, Nordenholz KE, Moore CL, et al. Factors associated with positive $\mathrm{D}$-dimer results in patients evaluated for pulmonary embolism. Acad Emerg Med 2010;17: 589-97.

18. Gardiner C, Pennaneac'h C, Mackie IJ, Sheldrake A,
Harrison J, Machin SJ. Falsely elevated D-dimer results in a healthy patient on account of heterophiletul antibodies. Br J Haematol 2003;122:871-3.

19. Tobbia D, Semple J, Baker A, Dumont D, Semple A, Johnston M. Lymphedema development and lymphatic function following lymph node excision in sheep. J Vasc Res 2009;46:426-34.

20. Guc E, Briquez PS, Foretay D, Fankhauser MA, Hubbell JA, Kilarski WW, et al. Local induction of lymphangiogenesis with engineered fibrin-binding VEGF$\mathrm{C}$ promotes wound healing by increasing immune cell trafficking and matrix remodeling. Biomaterials 2017; 131:160-75.

21. Kim C, Li B, Papaiconomou C, Zakharov A, Johnston M. Functional impact of lymphangiogenesis on fluid transport after lymph node excision. Lymphology 2003;36:111-9.

22.Zampell JC, Avraham T, Yoder N, Fort N, Yan A, Weitman ES, et al. Lymphatic function is regulated by a coordinated expression of lymphangiogenic and antilymphangiogenic cytokines. Am J Physiol Cell Physiol 2012;302:C392-404.

23. Welsh JD, Kahn ML, Sweet DT. Lymphovenous hemostasis and the role of platelets in regulating lymphatic flow and lymphatic vessel maturation. Blood 2016;128:1169-73.

24. McColl BK, Baldwin ME, Roufail S, Freeman C, Moritz RL, Simpson RJ, et al. Plasmin activates the lymphangiogenic growth factors VEGF-C and VEGF-D. J Exp Med 2003;198:863-8.

25. Bui HM, Enis D, Robciuc MR, Nurmi HJ, Cohen J, Chen M, et al. Proteolytic activation defines distinct lymphangiogenic mechanisms for VEGFC and VEGFD. J Clin Invest 2016;126:2167-80.

26. de Abreu Junior GF, Pitta GB, Araujo M, Castro Ade A, de Azevedo Junior WF, Miranda Junior F. Ultrasonografic changes in the axillary vein of patients with lymphedema after mastectomy. Rev Col Bras Cir 2015;42:81-92.

27. Baarslag HJ, van Beek EJ, Koopman MM, Reekers JA. Prospective study of color duplex ultrasonography compared with contrast venography in patients suspected of having deep venous thrombosis of the upper extremities. Ann Intern Med 2002;136:865-72. 